[This is a pre-print of a paper forthcoming in Proceedings of the 12th Kant Congress. Edited by Violetta Waibel and Margit Ruffing. Berlin: De Gruyter, 2018.]

\title{
Kant's Antinomy of Teleology: In Defense of a Traditional Interpretation
}

Uniquely, Kant gives two formulations of an opposition in the Antinomy of Teleology, one between regulative, the other between constitutive principles. This has given rise to considerable dispute over which pair represents the real Antinomy, which, naturally, has consequences for interpreting its resolution. According to the "Traditional View", an apparent antinomy resides in the constitutive pair, and is resolved by noting the confusion of merely regulative maxims as constitutive principles. On the "New Orthodoxy"2, however, the regulative theses are themselves antinomial. The latter view owes in large part to perceived problems of squaring the Traditional View with the broader structure of the Dialectic of Teleology. Here, I argue in defense of the Traditional View: I first present the antinomy and its resolution, then respond to several objections to it rooted in perceived textual worries. Throughout, I emphasize hitherto neglected parallels with the Antinomy of Taste that shed light on the Antinomy of Teleology.

A dialectic of the power of judgment in its reflecting use, in general, consists in the opposition of judgments that make a claim to universality and necessity. However, as merely reflecting judgment, this is subjective, not objective, universality. That is, a

${ }^{1}$ Erich Adickes, Kant als Naturforscher, bd. 2 (Berlin, 1925), 473-4; Ernst Cassirer, Kants Leben und Lehre (Berlin, 1921), 369; August Stadler, Kants Teleologie und ihre erkenntnistheoretische Bedeutung (Berlin, 1874), 128. A more recent defense of this position is in Marcel Quarfood, Transcendental Idealism and the Organism (Stockholm, 2004).

${ }^{2}$ John McFarland, Kant's Concept of Teleology (Edinburgh, 1970), 118; Peter McLaughlin, Kant's Critique of Teleology in Biological Explanation (Lewiston, 1990), 134-6; Henry Allison, "Kant's Antinomy of Teleological Judgment." The Southern Journal of Philosophy, 30 Supplement (1991): 25-42; Eric Watkins, "The Antinomy of Teleological Judgment.” Kant Yearbook, 1 (2009): 197-221. 
conflict, hence the appearance of an antinomy, obtains only to the extent that the statements lay claim to necessity and universality that bind the judgments of other subjects, but without laying claims about any objective determinations. So, in the case of aesthetic judgment, an antinomy arises with respect to two maxims, one of which claims that judgments of taste are founded on concepts (otherwise it would not be possible to argue in matters of taste), while the other denies it (otherwise claims of taste could be adjudicated by rational proofs, which they are not). So, Kant resolves the antinomy by exposing an equivocation in the sense of 'Begriff' in the two statements. The solution lies in treating the predicate of an aesthetic judgment, not as a determinate concept of the object, but as a concept that is "in itself indeterminable" (KU AA 5:340.17). Then, the thesis, that the judgment of taste is not based on concepts, can be taken as universally valid, insofar as the statement does not make an objective claim on the basis of a determinate concept, thereby does not admit a rational proof; and the antithesis, that the judgment of taste is based on concepts, can be treated as universally valid, since it is possible to argue about taste without making determinate objective claims. Thus, the resolution of the antinomy consists in exposing a confusion in the relation between the concept and the object that is judged. ${ }^{3}$

In its teleological use the power of judgment becomes antinomial in a similar manner. Its conflicting judgments pertain to its reflection on one kind of object, namely, Naturzwecke or organisms. In the absence of mechanical schematisms through which the generation of organisms can be explained in the same way as the motions of bodies, the

\footnotetext{
${ }^{3}$ KU AA 5:337-41. This reading of the Antinomy of Taste agrees with: Henry Allison, Kant's Theory of Taste: A Reading of the Critique of Aesthetic Judgment, (Cambridge, 2001); Paul Guyer, Kant and the Claims of Taste, (Cambridge, 1997).
} 
power of judgment proceeds under the presupposition of a purposiveness of nature, in accordance with which Naturzwecke would be formed. To direct its inquiries in such cases, the power of judgment relies on regulative maxims, which, while eschewing claims to objective validity, are able to serve the cognitive faculties in their investigation into empirical laws of organisms. These maxims are, indeed, necessary, for otherwise there would be no possibility of ascending to higher unities of empirical laws of nature. Without such maxims, in other words, cognition would come to a standstill upon encountering objects for which the understanding does not have concepts. Consequently, Kant writes that such maxims are needed to arrive at concepts, even if these are "Vernunftbegriffe". Thus, a conflict arises between the maxims of the power of judgment once competing claims of the cognitive faculties become involved in the search for empirical laws. In particular, when each of two maxims of the reflecting power of judgment is grounded in separate cognitive faculties, a "natural dialectic" and an "unavoidable illusion" comes about (KU AA 5:386.2-9). It is this condition of the faculties that needs to be diagnosed so that we are not deceived.

With this set up, Kant presents the antinomy of teleological judgment by contrasting the specification of nature with respect to its universal as opposed to its particular laws. For the application of the universal laws of matter and motion, the power of judgment relies wholly on objective principles given to it by the understanding. In the case of the particular laws of empirical nature, however, the determining power of judgment alone is insufficient, for the schematisms of the understanding do not offer grounds to decide between one or another set of particular empirical laws. The power of judgment, thus, requires maxims of reflection with which to orient its investigation into 
the contingent unity of particular laws. For this task, each of the other two, higher faculties supplies it with a principle, the understanding in accordance with its categories, and reason in accordance with its demand for the unconditioned in the series of appearances for which the understanding is inadequate. ${ }^{4}$ Thus, a conflict results between the following maxims: "All generation of material things and their forms must be judged as possible in accordance with merely mechanical laws."; and "Some products of material nature cannot be judged as possible according to merely mechanical laws (judging them requires an entirely different law of causality, namely that of final causes)" (KU AA 5:387.3-9).

Each statement makes a claim with respect to the manner in which the generation of material things is to be judged. The thesis represents the understanding's interest in cognition of nature, that all material objects be judged in accordance with the laws of mechanical nature. The antithesis, by contrast, represents reason's interest in cognition of nature, inasmuch as certain appearances resist mechanistic explanation, thus demand a different kind of causality. The reconciliation of this apparent opposition is achieved by noting that these maxims are in fact merely subjectively valid for the reflecting use of the power of judgment, and not objectively valid for cognition. The resolution of the conflict between the maxims of the power of judgment in its teleological context, as in the aesthetic one, requires exposing a confusion, in this case that of confusing principles of the reflecting with ones of the determining power of judgment.

${ }^{4}$ KU AA 5:386.29-34. 
Indeed, as Kant points out, there is in fact no contradiction here at all. ${ }^{5}$ For the thesis does not assert that all material objects are possible only in accordance with mechanical laws, but just that "I should always reflect on them in accordance with the principle of the mere mechanism of nature"' (KU AA 5:387.31-33). Thus construed, the thesis does not conflict with the second maxim, which only requires that in some cases investigation should be guided by the principle of final causes. The use of the teleological maxim does not exclude the use of the mechanistic one, but rather presupposes it. ${ }^{6}$ For even Naturzwecke must first be judged as part of the system of nature, thus governed by the laws of mechanism, before teleological principles can be employed to investigate their special characteristics as organized beings. Furthermore, the employment of the teleological maxim does not rule out the possibility that even natural organized beings might have originated through purely mechanical processes. Rather, it only claims that it is not possible for $u s$ to judge organisms as such. It is a limitation of human reason that requires our dependence on appeal to final causes, but we should not thereby infer that organisms themselves are constituted through ends. ${ }^{7}$ Thus, the apparent conflict between the maxims is readily resolved, once certain confusions are cleared and the statements seen to be compatible. Indeed, Kant writes:

All appearance of an antinomy between the maxims of that kind of explanation which is genuinely physical (mechanical) and that which is teleological (technical) therefore rests on confusing a fundamental principle of the reflecting with that of the determining power of judgment. (KU AA 5:389.20-27)

\footnotetext{
5 "Was dagegen die zuerst vorgetragene Maxime einer reflectirenden Urtheilskraft betrifft, so enthält sie in der Tat gar keinen Widerspruch" (KU AA 5:387.25-26).

${ }^{6}$ KU AA 5:388.3-6.

${ }^{7}$ KU AA 5:388.13-19.
} 
The appearance of an antinomy, thus, results from confusing Maximen for the following, constitutive principles: "All generation of material things is possible in accordance with merely mechanical laws"; and "Some generation of such things is not possible in accordance with merely mechanical laws" (KU AA 5:387.13-16). The constitutive principles represent a true contradiction, and an irreconcilable antinomy threatens. However, Kant writes, this would not be an antinomy of the power of judgment, but "a conflict in the legislation of reason" (KU AA 5:387.20-21). For, so formulated, the antinomy arises from the opposing claims of understanding and reason to objective knowledge, in the pursuit of which the power of judgment would operate in its determining function. Under such principles, the power of judgment would not need its maxims for reflection, since it would be given constitutive principles. Unfortunately though, reason is in no position to prove either of these principles, since it can have no a priori principle for determining the possibility of objects in accordance with empirical laws of nature. ${ }^{8}$ The a priori principles of reason and understanding have their legitimate use only with respect to the domain of moral action, and to the universal laws of material nature, respectively. But the generation of organisms requires specifying empirical laws of nature and, as such, is decidable neither by the moral law, nor by the laws of matter in motion alone. Thus, the antinomy cannot be resolved to show, for instance, that both statements are false (as in the mathematical antinomies), or that both can be true (as in the dynamical antinomies), or that one is valid from the sensible and the other from the intelligible standpoint (as in the antinomy of pure practical reason).

${ }^{8}$ KU AA 5:387.22-24. 
To sum up, Kant presents two ways in which the power of judgment might be led into conflict with itself. In the first place, a merely apparent opposition arises between two of its maxims. However, this illusion of conflict is dissolved once each maxim is understood in its proper sense, and the domain of application of each is made clear. Kant goes further, in fact, to claim that, not only is there no contradiction between the two maxims, but that each is needed for a proper investigation of nature. In the second place, a true contradiction arises when regulative maxims are treated as constitutive principles issued from the understanding and reason. Being a true contradiction due to a transgressive legislation of a priori principles, this conflict cannot be resolved, for it requires settling conclusively a question about particular empirical laws of nature.

I will now consider four objections that have led commentators to reject the foregoing interpretation in favor of the "New Orthodoxy" - that a genuine antinomy resides in the regulative maxims, the resolution of which is the task of $\S \S 71-78$.

The first objection claims that the Traditional View sits in tension with Kant's promise to provide an antinomy of the reflecting power of judgment, whereas the constitutive principles belong to determining judgment. ${ }^{9}$ This remark alone, however, does not tell us whether the antinomy should be located in the regulative pair or the constitutive pair of theses. In each case the thesis/antithesis pair is supplied to the power of judgment by the understanding and reason, respectively, hence is grounded in a priori principles of the cognitive faculties, as required for a dialectic. Moreover, as Kant explicitly states, the maxims of reflecting judgment do not in fact contradict. ${ }^{10}$ Thus, Kant's opening remarks in the Dialectic are insufficient to establish whether an antinomy

\footnotetext{
${ }^{9}$ McLaughlin (1990, 138); Allison (1991, 30); Watkins (2009, 200).

${ }^{10}$ KU AA 5:387.25-26
} 
holds between the regulative or the constitutive pair of theses. In fact, it is worth bearing in mind that a two-fold formulation of an antinomy is possible for the critique of taste as well, a circumstance of which Kant is aware. While Kant doesn't explicitly provide two formulations in the Dialectic of Taste, he notes that a dialectic can only be a "dialectic of the critique of taste (not of taste itself)" (KU AA 5:337.14-15). Kant is concerned to note this fact before presenting the antinomy of taste, precisely because of a similar danger of confusing a principle of judging about taste with principles of taste itself. Such danger is more acute in the case of teleological judging, since the purposiveness of nature in dispute here is objective.

The second objection asserts that, since reason cannot prove either of the two constitutive principles, the antinomy cannot hold between them, for, at least on the model of the antinomies of the first Critique, the theses must have formal proofs. ${ }^{11}$ However, it is equally unclear what the proofs of the regulative theses might be. One might be inclined to think that Kant's deductions of the Newtonian laws in the Metaphysische Anfangsgründe provide the proof for the mechanist maxim. But that cannot be sufficient, for what is it at issue in the third Critiqueis the discovery of particular empirical laws of natural formations, rather than universal laws of moving bodies. What's more, Kant is explicit that the impossibility of the generation of Naturzwecke through mere mechanism cannot be proven, thus making possible the constitutive theses. ${ }^{12}$ That is, Kant must think that there is some argument for the logical possibility that Naturzwecke are generated through mechanical processes. Finally, even the proofs of the theses and antitheses of the

\footnotetext{
${ }^{11}$ Watkins $(2009,200)$

${ }^{12}$ KU AA 5:388.22-23.
} 
cosmological antinomies of the first Critiqueare only indirect. ${ }^{13}$ Thus, the demand of direct proofs is nowhere required, and indirect proofs are forthcoming for both the regulative and constitutive statements of the antinomy. The second objection provides equally little reason to favor one or the other interpretation of the antinomy.

Third, it is objected that a Kantian antinomy is not a mere confusion, as the Traditional View would have it. Rather, it is a deep illusion stemming from the nature of the cognitive faculties. ${ }^{14}$ This objection incorrectly takes the antinomies of the first Critique as the model for all Kantian antinomies. As Hinske argues, Kant's use of the figure of the antinomy develops over time, and has multiple meanings even in the first Critique. ${ }^{15}$ Setting aside the cosmological antinomies, and focusing on the specific context of the critique of the power of judgment, it is clear that not all antinomies stem from formal logical oppositions. In particular, the antinomy of the critique of taste amounts to pointing out an equivocation in two senses of 'Begriff', as noted above, thus is closer to the manner in which the antinomy of teleology is resolved, than are the antinomies of the first and second Critiques. Unlike the latter, the resolution of the antinomies of the third Critique requires uncovering a rhetorical fallacy, and a conflict among the cognitive faculties. This should hardly be surprising since these antinomies are drawn neither from the faculty of concepts, nor of inference, but from Urteilskraft.

Finally, commentators worry that, on the Traditional View, $\S \S 71-78$ appear to be superfluous. If Kant resolves the antinomy almost as soon as he presents it, why did he

\footnotetext{
${ }^{13}$ As McLaughlin notes $(1990,129)$.

${ }^{14}$ McLaughlin (1990, 360); Allison (1991, 31)

${ }^{15}$ Norbert Hinske, "Kants Begriff der Antinomie und die Etappen seiner Ausarbeitung", Kant Studien, 56 (1965): 485-96.
} 
bother to write the remaining sections of the Dialectic of Teleology? ${ }^{16}$ But the subsequent sections remain crucial, though not, strictly speaking, for the resolution of the antinomy. For Kant still owes his readers a diagnosis of why we are led to confuse regulative maxims for constitutive principles. Kant begins this diagnosis by exposing as inadequate, in $\S \S 72-73$, four dogmatic approaches - the Epicurean, the Spinozist, the hylomorphist, and the theistic - for resolving the tension between mechanical and teleological principles of judging nature. $\S \S 74-75$ argue further for the impossibility of a dogmatic judgment of the laws of generation of organized beings. This diagnosis not trivial, for it is rooted in a central Kantian insight that,

if things are subsumed under a concept that is merely problematic, the synthetic predicates of such a concept... must yield the same sort of (problematic) judgments of the object, whether they are affirmative or negative, since one does not know whether one is judging about something or nothing. (KU AA 5: 397.713).

Since the maxims of reflecting judgment are never entitled to make constitutive claims about objects, one can never make synthetic existence claims about the final causes of Naturzwecke without falling into an antinomial confusion of taking regulative principles for constitutive ones. Thus, Kant famously declares the impossibility of a Newton, who could explain according to the laws of nature the generation of a blade of grass. ${ }^{17}$ Then, in the vastly influential $\S \S 76-77$, Kant locates the impossibility of a dogmatic reconciliation of mechanism and teleology, with respect to the discovery of empirical laws of nature, in a profound chasm between the nature of our discursive intellect and

\footnotetext{
${ }^{16}$ McFarland (1970, 121); Watkins (2009, 200)

${ }^{17}$ KU AA 5:400.16-20.
} 
that of an intuitive intellect. This discussion gets to the deep source in the nature of the cognitive faculties of the confusion between regulative and constitutive principles of judging, such that the dialectic of mechanism and teleology appears natural and avoidable, thus requiring a transcendental critique. $§ 78$, finally, cannot strictly be considered part of the treatment of the antinomy, for it presses beyond a diagnosis of the confusion of regulative and constitutive principles, to affirm that mechanism and teleology are not only compatible, but are in fact unifiable, albeit in a transcendent idea of the supersensible. ${ }^{18}$ Once again, it is instructive to see the parallel in the conclusion of the Dialectic of Taste, where Kant affirms the indeteminate idea of the supersensible as of a "substrate of nature" as well as of a "principle of the subjective purposiveness of nature for our cognitive faculties" (KU AA 5:346.16-18).

The Traditional View, I submit, is the more natural way to read the Antinomy of Teleology, as most of its detractors concede. The reason for the emergence of the "New Orthodoxy", I suspect has to do with the apparent textual discord with the rest of the Dialectic. In this paper, I hope to have cleared some of that appearance of discord, and thus contributed to restoring the more straightforward meaning of Kant's text.

${ }^{18}$ KU AA 5:414.12-15. 